\title{
URBANO, Hudinilson (2000). Oralidade na literatura (O caso Rubem Fonseca). São Paulo: Cortez, 288 p.
}

Luiz Antônio da Silva *

tualmente, percebem-se mudanças significativas no pro-
cesso de comunicação. Alguns dizem que não se fala nem se escreve como antigamente. Outros afirmam que, em tempos remotos, os usuários da lingua sabiam cuidar bem do falar e do escrever, hoje não mais. Não se pode esquecer que os tempos, de fato, mudam e a lingua não fica imune a essas transformações culturais. No dia-a-dia, especialistas e leigos comunicam-se por meio do uso comum da língua; na literatura, é forte a presença da linguagem cotidiana.

De forma mais ou menos acentuada, em diversas épocas, os escritores foram impelidos a retratar em suas obras a influência da lingua falada. Sem dúvida, os escritores contemporâneos têm buscado estratégias para transformar o coloquial do cotidiano em matéria artística.

Dentre esses autores, José Rubem Fonseca é um dos mais significativos. Suas obras caracterizam-se por um realismo feroz, cruel, violento da sociedade como um todo. Seus temas exploram o conflito social, a violência, a desumanização, a hipocrisia burguesa. É um escritor que desperta interesse pela vinculação à problemática da lingua falada popular contemporânea. 
Retomando e atualizando sua tese de doutorado - Oralidade na literatura (O Caso Rubem Fonseca), Hudinilson Urbano explora essa problemática. Ele elabora uma minuciosa análise lingüistica e estilística do escritor mineiro, tomando como parâmetros os fundamentos teóricos da Lingüîstica, da Análise da Conversação, da Sociolingüística, da Pragmática, da Estilistica e da Teoria Literária. Conforme diz Dino Preti na "Apresentação", o objetivo do trabalho "é mostrar como o autor conscientemente se utiliza da oralidade, criando novos efeitos no processo narrativo e no diálogo de suas personagens".

O autor é professor de Lingua Portuguesa da Faculdade de Filosofia, Letras e Ciências Humanas da Universidade de São Paulo. Temse destacado como pesquisador ligado ao Projeto NURC/SP (Projeto da Norma Lingüística Urbana Culta da Cidade de São Paulo). Nesse projeto, tem-se dedicado ao estudo especifico da lingua falada e das suas relações com a lingua escrita. Suas pesquisas abrangem, sobretudo, as estratégias e os mecanismos de produção do texto oral.

O olhar atento e o cuidado do pesquisador Hudinilson Urbano ficam evidentes na organização do trabalho. A obra está dividida em duas partes distintas e com funções bem especificas. A primeira, panorama teórico-metodológico, trata de vários assuntos teóricos, dentre os quais enunciação/enunciado; narrativa oral/narrativa escrita; variedades lingüisticas; modalidades lingüísticas: língua falada/lingua escrita. A segunda parte, a representação da oralidade em Rubem Fonseca, analisa o material selecionado e coloca em prática os componentes teóricos da primeira parte.

Fundamentado em teóricos como Benveniste, Ducrot, Todorov, Kerbrat-Orecchioni, entre outros, no primeiro capitulo, o autor processa um vasto painel sobre questões relativas à enunciação, enunciado e marcas da enunciação. No segundo capítulo, aborda aspectos da narrativa oral e narrativa escrita, planos da narrativa, tipologia do narrador, discurso direto, indireto e indireto livre. O terceiro capítulo está dedicado às variedades lingüisticas. Nessa seção, há o propósito de estudar os diversos niveis de linguagem e os fatores que levam a 
essa variação. Lingua falada e lingua escrita constituem o tema principal do quarto e último capitulo da primeira parte. Nele, há reflexões importantes sobre a estrutura, modo de aquisição, meios de produção, transmissão e recepção das modalidades falada e escrita. Nesse capitulo, há um substancial estudo sobre as caracteristicas especificas da língua falada, complementado pela interessante observação da página 131, ao finalizar a primeira parte: "Como fecho do capitulo e das considerações de ordem teórica, consignamos a observação sobre conversação real e conversação literária de Criado de Val (1980: 15-7), que, como já salientamos, distingue conversação e narração na fala, aproximando, sob certos aspectos, a narração oral à escrita e mesmo à escrita literária".

Depois de compor um painel dos protagonistas responsáveis pela estrutura narrativa, há a preocupação de observar como e em que nível e medida esses diversos protagonistas realizam os atos de fala, representando diversos papéis dentro das diversas situações de fala. A segunda parte da obra analisa o material selecionado. No primeiro capitulo, existe a preocupação de esclarecer o critério de seleção dos contos. Foram selecionados oito contos da obra geral do escritor Rubem Fonseca: "Fevereiro ou março", "Gazela", "A força humana", "Desempenho", "O caso de F. A.", "Botando pra quebrar", "Pierrô da caverna" e "O jogo do morto". Segundo Urbano (p.136), a escolha "atendeu a critérios de distribuição da produção no tempo; da sugestão da "crítica"; da diversificação temática e de alguma recorrência de personagens em alguns contos. Todavia, mais que qualquer critério, inclusive de valor literário, prevaleceu o interesse pelo enfoque lingüistico no atendimento à expectativa de uma abordagem mais diversificada possivel em relação ao universo teörico ventilado". No segundo, trabalha-se a questão da formalidade e informalidade da narrativa literária. Esse também é um ponto que merece reflexão cuidada. Nas páginas 136 e 137, o autor explicita: "Essa noção de formalidade/informalidade abrange dimensões diversas, que se implicam e se explicam mutuamente. Aqui estamos pensando em formalidade/informalidade na pro- 
essa variação. Lingua falada e lingua escrita constituem o tema principal do quarto e último capitulo da primeira parte. Nele, há reflexões importantes sobre a estrutura, modo de aquisição, meios de produção, transmissão e recepção das modalidades falada e escrita. Nesse capitulo, há um substancial estudo sobre as caracteristicas especificas da lingua falada, complementado pela interessante observação da página 131, ao finalizar a primeira parte: "Como fecho do capitulo e das considerações de ordem teórica, consignamos a observação sobre conversação real e conversação literária de Criado de Val (1980: 15-7), que, como já salientamos, distingue conversação e narração na fala, aproximando, sob certos aspectos, a narração oral à escrita e mesmo à escrita literária".

Depois de compor um painel dos protagonistas responsáveis pela estrutura narrativa, há a preocupação de observar como e em que nivel e medida esses diversos protagonistas realizam os atos de fala, representando diversos papéis dentro das diversas situações de fala. A segunda parte da obra analisa o material selecionado. No primeiro capitulo, existe a preocupação de esclarecer o critério de seleção dos contos. Foram selecionados oito contos da obra geral do escritor Rubem Fonseca: "Fevereiro ou março", "Gazela", "A força humana", "Desempenho", "O caso de F. A.", "Botando pra quebrar", "Pierrô da caverna" e "O jogo do morto". Segundo Urbano (p.136), a escolha "atendeu a critérios de distribuição da produção no tempo; da sugestão da "crítica"; da diversificação temática e de alguma recorrência de personagens em alguns contos. Todavia, mais que qualquer critério, inclusive de valor literário, prevaleceu o interesse pelo enfoque lingüístico no atendimento à expectativa de uma abordagem mais diversificada possivel em relação ao universo teórico ventilado". No segundo, trabalha-se a questão da formalidade e informalidade da narrativa literária. Esse também é um ponto que merece reflexão cuidada. Nas páginas 136 e 137, o autor explicita: "Essa noção de formalidade/informalidade abrange dimensões diversas, que se implicam e se explicam mutuamente. Aqui estamos pensando em formalidade/informalidade na pro- 
dução narrativa e, em especial, na narrativa literária, em que, na realidade, a informalidade se faz por simulação. Será tanto mais informal quanto mais revelar um tom de descompromisso com as técnicas, regras e fórmulas especiais e complexas, um tom de narrativa oral coloquial, isto é, como se produzida distensamente para ouvintes à frente, como se despreocupada com o rigor na linguagem, no plano organizacional e na interligação lógica dos fatos e circunstâncias, na seqüência tópica cronológica, com situações dramáticas mais ou menos bem caracterizadas e delimitadas, com correlação planejada de incidentes e parágrafos, atingindo o leitor com uma sensação desconcertante. Tudo ao contrário caracterizaria uma narrativa mais formal, elaborada". Já no terceiro capitulo, trata-se da linguagem dos contos e a importância da linguagem como elemento caracterizador da formalidade e da informalidade da narrativa. Nesse capitulo, destacam-se as seções dedicadas à problemática da competência lingüística e do desempenho lingüístico do narrador e das personagens. E finaliza (p. 263) asseverando que "as análises realizadas nos contos selecionados comprovam a hipótese de que Rubem Fonseca incorporou o registro da oralidade, aqui entendida como lingua falada popular, onde, como e quanto lhe permitiam a verossimilhança e o canal escrito, realizando assim, à sua maneira, a linguagem literária desses contos".

Nessa perspectiva, fica evidente que a obra de Hudinilson Urbano interessa a lingüistas e a estudiosos da literatura. Há uma bem feita imbricação de elementos literários e lingüisticos, como afirma na página 15: "Da modernidade lingüística pode-se dizer que é concebida como objeto portador de realidade própria. É como se esse meio, a linguagem, se transformasse, ela mesma, em 'fim', a tal ponto que, em certos contos, o seu vigor parece ofuscar o das próprias ações. Na realidade, as ações lingüísticas (o uso lingüístico) coocorrem, e muitas vezes parecem concorrer, com as demais ações extralingüisticas do enredo".

Outros valores acentuam a substancialidade do trabalho de Urbano. Sem fazer parte do corpo do trabalho, há mais duas seções 
que revelam o cuidado que ele tem com seus leitores e deixa claro o perfil de pesquisador esmerado. Trata-se da bibliografia e do índice remissivo.

Para facilitar o trabalho de leitura, há divisão da bibliografia em três partes: bibliografia geral; bibliografia abrangendo dicionários de linguagens especificas, gírias, termos e expressões populares, incluindo dicionários comuns que registram tais usos; bibliografia sobre o autor estudado. Especialmente aqueles que desejam estudar questões relativas à lingua falada, oralidade, lingua falada e lingua escrita têm a seu dispor uma ampla e rica fonte de textos especificos sobre o assunto.

Por outro lado, ainda revelando o perfil do pesquisador sério, teve o cuidado de organizar um excelente índice remissivo, item que já não se encontra em obras de divulgação. Acrescente-se, ainda, a excelente "Apresentação" de Dino Preti, que, por si só, representa uma boa resenha da obra e antecipa questões importantes a serem discutidas e refletidas.

É inegável a importância da obra de Hudinilson Urbano, pois trata-se de pesquisa altamente significativa no plano lingüistico e literário. Para os estudiosos da Análise da Conversação, esta obra oferece a oportunidade de conhecer, rever e reavaliar as possibilidades da lingua falada e seu dificil processo de representação na literatura.

Escrita numa linguagem adequada e fluente, a obra deve ser consulta obrigatória de estudantes de Letras, pesquisadores, críticos literários e amantes da literatura. 